\title{
An improved equation for unsaturated shear strength behavior of soils
}

\author{
Hossain Md Sayem ${ }^{\text {i) }}$, Ling-wei Kong ${ }^{\text {ii) }}$ and Yong Wang ${ }^{\text {iii) }}$
}

\begin{abstract}
i) Associate Professor, Department of Geological Sciences, Jahangirnagar University, Dhaka-1342, Bangladesh. ii) Professor, State Key Laboratory of Geomechanics and Geotechnical Engineering, Institute of Rock and Soil Mechanics, Chinese Academy of Sciences, Wuhan, Hubei 430071, China.

ii) Associate Professor, State Key Laboratory of Geomechanics and Geotechnical Engineering, Institute of Rock and Soil Mechanics, Chinese Academy of Sciences, Wuhan, Hubei 430071, China.
\end{abstract}

\begin{abstract}
The mechanical behavior of unsaturated soils is one of the challenging topics in the field of geotechnical engineering due to world-wide distributions and construction of most engineered earth structures within these soils. However, the study of unsaturated soil behavior is complex because its pore space is partially filled with water and air. The shear strength of unsaturated soils is defined by using two independent stress state variables i.e. net normal stress $\left(\sigma-\mu_{\mathrm{a}}\right)$ and matric suction $\left(\mu_{\mathrm{a}}-\mu_{\mathrm{w}}\right)$. Direct measurements of unsaturated shear strength in laboratory are complicated, expensive, time consuming and required specialized testing equipment. An improved equation for unsaturated shear strength behavior of soils is proposed in this paper. The validity of the proposed improve method is examined for a number of suction strength data of different kind of soils available in the literature. It is found that the suction strength values predicted from the proposed equation are in well agreement with the experimental results. Furthermore, the proposed improve equation is also compared with some previously published suction strength equations using those known experimental data. The results show that most of the previously published equations are suitable for particular types of soil whereas the proposed equation provides well agreement for different types of soils. Therefore, the proposed improve equation is more suitable for the prediction of the suction strength and quite adequate for practical engineering purposes.
\end{abstract}

Keywords: unsaturated soil, net normal stress, matric suction, SWCC, suction strength.

\section{INTRODUCTION}

The mechanical behavior of unsaturated soils is one of the challenging topics in the field of geotechnical engineering due to world-wide distributions and construction of most engineered earth structures (such as earth dams, retaining walls, railway tract and road embankments, liners and covers of waste disposal etc.) within these soils. Numerous geotechnical problems and diseases are also associated with unsaturated soils including heave, landslides, settlements and subsidence, damage of pavements and collapse. Last 50 years, many researchers have made significant contribution to the understanding of the unsaturated soil mechanical behaviors. In many of these studies, the shear strength of unsaturated soils has an important role because of its knowledge reproduces more closely the real condition in which the soil is submitted in the field. However, the behavior of unsaturated soil behavior is complex because its pore space is partially filled with water and air (Lambe and Whitman 1969). Unlike saturated soils, the shear strength of unsaturated soils depends on two independent stress-state variables i.e. net normal stress $\left(\sigma-\mu_{\mathrm{a}}\right)$ and the matric suction $\left(\mu_{\mathrm{a}}-\mu_{\mathrm{w}}\right)$ suggested by numerous authors (e.g. Bishop 1959; Aitchinson 1961; Jennings 1961; Bishop and Blight 1963; Fredlund and Morgenstern 1977). The matric suction is one of the main variables in unsaturated soil mechanics for predicting the hydraulic conductivity, soil water storage, and shear strength of unsaturated soils (Fredlund and Rahardjo 1993). Many researchers examined the contribution of matric suction to the shear strength of unsaturated soils (which is termed as suction strength) and found that matric suction can largely influence the shear strength of unsaturated soils (e.g. Escario and Saez 1986; Fredlund et al. 1996; Vanapalli et al. 1996a; Rassam and Williams 1997; Miao et al. 2002; Toll and Ong 2003; Tekinsoy et al. 2004; Xu 2004).

The main objective of this study is to propose an improved equation for describing the non-linear behavior of suction strength with respect to matric suction. The validity of the proposed equation is also being tested for a number of unsaturated shear strength data as well as being compared with some published suction strength equations. 


\section{SHEAR STRENGTH FUNCTIONS FOR UNSATURATED SOILS}

Bishop (1959) proposed shear strength equation for unsaturated soils by extending Terzaghi's principle of effective stress for saturated soils, which is-

$$
\tau_{f}=c^{\prime}+\left(\sigma-\mu_{a}\right) \tan \phi^{\prime}+\chi\left(\mu_{a}-\mu_{w}\right) \tan \phi^{\prime}
$$

Where, $\mathrm{c}^{\prime}=$ effective cohesion; $\phi^{\prime}=$ effective friction angle; $\left(\sigma-\mu_{\mathrm{a}}\right)=$ net normal stress; $\left(\mu_{\mathrm{a}}-\mu_{\mathrm{w}}\right)=$ matric suction; and $\chi=$ effective stress parameter depending on the degree of saturation, $\mathrm{S}_{\mathrm{r}}$. The value of $\chi$ varies from 1 for a saturated condition to 0 for a completely dry condition. The equation is also based on the assumption that the effective cohesion and the effective friction angle are independent of matric suction.

Fredlund et al. (1978) proposed the following equation for the shear strength of unsaturated soils-

$$
\tau_{f}=c^{\prime}+\left(\sigma-\mu_{a}\right) \tan \phi^{\prime}+\left(\mu_{a}-\mu_{w}\right) \tan \phi^{b}
$$

Where, $\phi^{\mathrm{b}}$ is the angle indicating the rate of increase in shear strength relative to the matric suction.

The first part of both equations is known as the saturated shear strength. The second part of these equations called suction strength is the shear strength contribution due to matric suction. From equation (1) \& (2), the relationship between the coefficient $\chi$ and $\phi^{b}$ is given by (3):

$$
\chi \tan \phi^{\prime}=\tan \phi^{b}
$$

It indicates that $\chi$ and $\phi^{\mathrm{b}}$ generate by the matric suction and both variables being dependent on matric suction or saturation. Up to the air entry value (AEV) where the soil remains essentially saturated, $\chi$ is equal to 1 and $\phi^{\mathrm{b}}$ is equal to $\phi^{\prime}$.

Beyond the AEV when the soil starts to desaturate, the values of $\chi$ and $\phi^{b}$ decrease gradually with the increase of matric suction and the relationship becomes non-linear (e.g. Gan et al. 1988; Vanapalli et al. 1996a; Lee et al. 2005). However, the direct measurement of $\chi$ and $\phi^{\mathrm{b}}$ are very complicated, expensive, time consuming and require specialized testing equipment in practice.

Numerous researchers suggested empirical approaches for the prediction of suction strength of unsaturated soils. In recent years, many shear strength equations are published for predicting or estimating the shear strength of unsaturated soil. Some of these equations are based on the soil-water characteristic curve (SWCC) along with the saturated shear strength parameters and others are based on mathematical fitting techniques. Some of those published suction strength prediction equations of unsaturated soils are

\begin{tabular}{|c|c|c|c|}
\hline Authors & Suction strength equations & No & Type \\
\hline Lamborn (1986) & $\tau_{\mu s}=(\theta)\left(\mu_{a}-\mu_{w}\right) \tan \phi^{\prime}$ & 4 & Prediction \\
\hline $\begin{array}{l}\text { Fredlund et al. (1996) and } \\
\text { Vanapalli et al. }\left(1996_{\mathrm{b}}\right)\end{array}$ & $\tau_{\mu s}=\left(\mu_{a}-\mu_{w}\right) \Theta^{\kappa} \tan \phi^{\prime}$ & 5 & Prediction \\
\hline Shen and Yu (1996) & $\tau_{\mu s}=\frac{\psi}{1+\psi \cdot d} \tan \phi^{\prime}$ & 6 & Fitting \\
\hline Vanapalli et al. $\left(1996_{b}\right)$ & $\tau_{\mu s}=\left(\mu_{a}-\mu_{w}\right) \frac{\theta-\theta_{r}}{\theta_{s}-\theta_{r}} \tan \phi^{\prime}$ & 7 & Prediction \\
\hline Oberg and Salfours (1997) & $\tau_{\mu s}=\left(\mu_{a}-\mu_{w}\right)(S) \tan \phi^{\prime}$ & 8 & Prediction \\
\hline Xu (1997) & $\tau_{\mu s}=k^{n}\left(\mu_{a}-\mu_{w}\right)^{m n+1} \tan \phi^{\prime}$ & 9 & Fitting \\
\hline Bao et al. (1998) & $\tau_{\mu s}=\left(\mu_{a}-\mu_{w}\right)\left[\frac{\log \left(\mu_{a}-\mu_{w}\right)_{r}-\log \left(\mu_{a}-\mu_{w}\right)}{\log \left(\mu_{a}-\mu_{w}\right)_{r}-\log \left(\mu_{a}-\mu_{w}\right)_{b}}\right] \tan \phi^{\prime}$ & 10 & Prediction \\
\hline Khalili and Khabbaz (1998) & $\tau_{\mu s}=\left(\mu_{a}-\mu_{w}\right)\left[\frac{\left(\mu_{a}-\mu_{w}\right)}{\left(\mu_{a}-\mu_{w}\right)_{b}}\right]^{-0.55} \tan \phi^{\prime}$ & 11 & Prediction \\
\hline Miao et al. (2002) & $\tau_{\mu s}=\frac{a \mu_{s}}{1+\frac{(1-a)}{P_{a t}} \mu_{s}}$ & 12 & Fitting \\
\hline Jiang et al. (2004) & $\tau_{\mu s}=\frac{\mu_{a}-\mu_{w}}{a+d .\left(\mu_{a}-\mu_{w}\right)} \tan \phi^{\prime}$ & 13 & Fitting \\
\hline Tekinsoy et al. (2004) & $\tau_{\mu s}=\tan \phi^{\prime}\left[\left(\mu_{a}-\mu_{w}\right)_{b}+P_{a t}\right] \operatorname{In}\left[\frac{\left(\mu_{a}-\mu_{w}\right)+P_{a t}}{P_{a t}}\right]$ & 14 & Prediction \\
\hline
\end{tabular}
summarized in Table 1.

Table 1. A summary of published suction strength prediction equations in unsaturated soils. 


\section{PROPOSED IMPROVE EQUATION FOR SUCTION STRENGTH}

The contribution of matric suction on shear strength (i.e suction strength) is well established and increases with increasing matric suction due to de-saturation and exhibits a non-linear relationship. The rate of de-saturation is not same with the rate of increasing matric suction. Hence, the increasing rate of suction strength reduces with increasing matric suction and will reach an approximately constant value at dry or nearly dry condition which can be explained by a typical shear strength versus matric suction curve (Fig. 1).

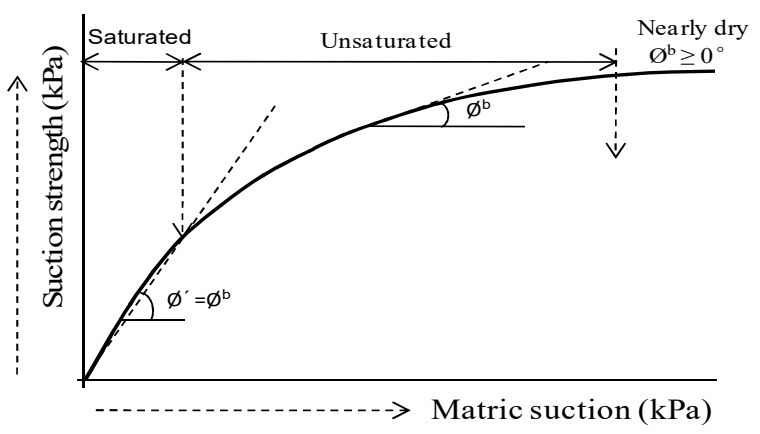

Fig. 1. A typical suction strength versus matric suction curve (modified after Tekinsoy et al., 2004).

During the study on strength property of gassy fine sand, Kong et al. (2005) developed a power function formula to describe the relationship between suction strength and matric suction of gassy sand which is-

$$
\tau_{\mu s}=a\left(\mu_{a}-\mu_{w}\right)^{b}
$$

The proposed improve suction strength equation of unsaturated soils is the modification of Kong et al. (2005) formula, which is-

$$
\tau_{\mu s}=\frac{a\left(\mu_{a}-\mu_{w}\right)^{b}}{1+c\left(\mu_{a}-\mu_{w}\right)^{b}}
$$

In addition, the corresponding formula for unsaturated shear strength is:

$$
\tau_{f}=c^{\prime}+\left(\sigma-\mu_{a}\right) \tan \phi^{\prime}+\frac{a\left(\mu_{a}-\mu_{w}\right)^{b}}{1+c\left(\mu_{a}-\mu_{w}\right)^{b}}
$$

Where, $\mathrm{a}, \mathrm{b} \& \mathrm{c}$ are fitting parameters. If matric suction $\left(\mu_{\mathrm{a}}-\mu_{\mathrm{w}}\right)$ is zero, $\tau_{\mu \mathrm{s}}$ is also equal to zero. In this equation, the value of $\mathrm{c}$ is greater or equal to zero (i.e. $\mathrm{c} \geq 0$ ) and the value of $\mathrm{b}$ ranges between 0 to 1 (i.e. $0 \leq \mathrm{b} \leq 1$ ).

From the formula (16), it can easily be seen that the $\mathrm{a} / \mathrm{c}$ has the physical meaning of suction strength $\left(\tau_{\mu \mathrm{s}}\right)$ limit value, b reflect suction strength-matric suction relation curve shape, and $\mathrm{a}$ is the reciprocal of slope for the relation of $1 / \tau_{\mu s}$ to $1 /\left(\mu_{\mathrm{a}}-\mu_{\mathrm{w}}\right)^{\mathrm{b}}$. Moreover, some other important features of this equation are-

1) When $\mu_{\mathrm{a}}-\mu_{\mathrm{w}} \rightarrow \infty \quad \tau_{\mu \mathrm{s}}=\mathrm{a} / \mathrm{c}$
2) If $\mathrm{c}=0$, then $\tau_{\mu \mathrm{s}}=\mathrm{a}\left(\mu_{\mathrm{a}}-\mu_{\mathrm{w}}\right)^{\mathrm{b}}$ and

3) If $\mathrm{b}=1 \& \mathrm{c}=0$, then $\tau_{\mu \mathrm{s}}=\mathrm{a}\left(\mu_{\mathrm{a}}-\mu_{\mathrm{w}}\right)$, where, $a=\tan \phi^{b}$.

\section{MATERIAL AND METHODS}

\subsection{Basic soil properties}

The undisturbed granite residual soil samples collected at areas (5.0-7.0 $\mathrm{m}$ depth) around Jiangmen city (Kaiping), Gaungdong province, China are used for this study. The studied soils are mainly composed of kaolinite with small amount of illite and the non-clay minerals include quartz, pyrite and gibbsite (Sayem et al. 2016). The basic material properties are measured in the laboratory and given in Table 2 and the obtained

\begin{tabular}{|c|c|c|c|c|c|c|}
\hline \multirow{2}{*}{$\begin{array}{l}\text { Depth } \\
\text { (m) }\end{array}$} & \multirow{2}{*}{$\underset{\left(\mathrm{g} / \mathrm{cm}^{3}\right)}{\mathbf{P}_{\mathbf{d}}}$} & \multirow{2}{*}{$\begin{array}{c}\text { MC } \\
\%\end{array}$} & \multicolumn{3}{|c|}{ Atterberg limits/\% } & \multirow{2}{*}{$\begin{array}{c}\% / \text { Free } \\
\text { swell }\end{array}$} \\
\hline & & & $\mathrm{L}_{\mathrm{L}}$ & $\mathrm{P}_{\mathrm{L}}$ & $\mathrm{I}_{\mathrm{P}}$ & \\
\hline $5.7 \sim 6.0$ & 1.30 & 40.20 & 57.1 & 30.7 & 26.4 & 9.75 \\
\hline
\end{tabular}
grain size distribution is shown in Fig. 2.

Table 2. Basic material properties of the studied residual soils.

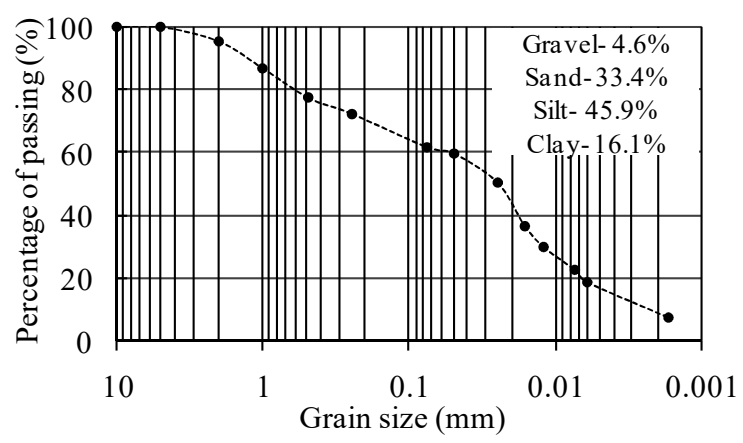

Fig. 2. Grain size distribution of the studied residual soil.

\subsection{Saturated shear strength \& SWCC of the soil}

A conventional triaxial test apparatus is used to measure the effective shear strength parameters of undisturbed soil specimens under consolidated drained conditions with the soil being in a saturated state according to ASTM D7181-11 (2011). The effective friction angle and the effective cohesion are determined as $24.95^{\circ}$ and $19.35 \mathrm{kPa}$, respectively and shown in Fig. 3 (Sayem et al. 2016).

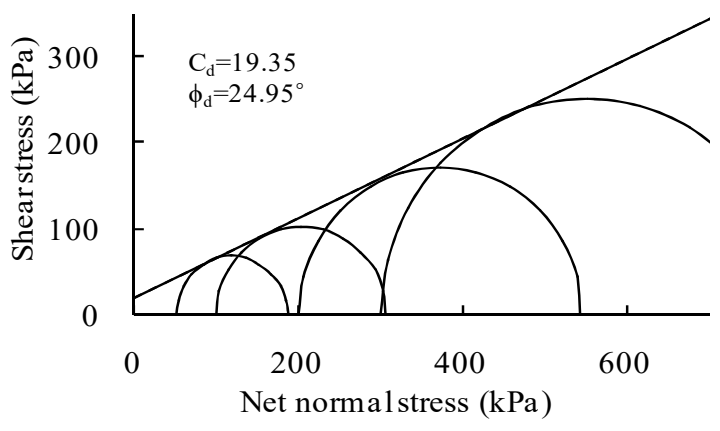

Fig. 3. Failure envelope of the saturated studied soil. 
The drying SWCC up to $1,500 \mathrm{kPa}$ suction is obtained experimentally on an undisturbed specimen using a pressure plate apparatus. The soil-water characteristic curve and the corresponding parameters are obtained using the van Genuchten (1980) model. Fig. 4 shows the SWCC of the studied soil with fitting parameters. The saturated vol. water content $\left(\theta_{\mathrm{s}}\right)$ and residual vol. water content $\left(\theta_{\mathrm{r}}\right)$ are $51.57 \%$ and $12.65 \%$ respectively (Sayem and Kong 2016).

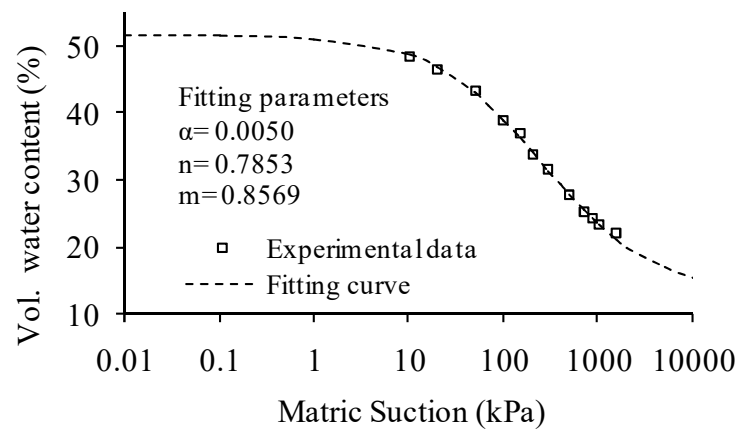

Fig. 4. Soil-water characteristic curve of the studied soil.

\section{RESULTS ABD DISCUSSIONS}

\subsection{Unsaturated shear strength of the studied soil}

To analyze the contribution of matric suction on the shear strength, the unsaturated shear strength of the studied undisturbed residual soils is calculated by using SWCC and saturated shear strength data. Vanapalli et al. $\left(1996_{\mathrm{b}}\right.$ ) proposed empirical model (equation 7 in Table 1) is used for this study. The predicted shear strength envelopes with respect to net normal stress show a linear behavior for all matric suctions (Fig. 5) whereas the variations of shear strength with respect to matric suction under constant net normal stress show a non-linear relationship (Fig. 6). This non-linearity of the failure envelope of unsaturated soil is due to the non-linear behavior of the SWCC. Beyond the AEV, the rate of desaturation is high with the increase of matric suction. After reaching the residual water content, the desaturation rate is reduced because the water begins to be held in the soil by adsorption forces and considerable matric suction is needed to drain even a small amount of water from the pores. This feature may also be an indication of the presence of large and small pores where larger pores desaturated first and then the smaller ones. Therefore, the matric suction has a contribution to the shear strength of unsaturated soils and this contribution called suction strength which varies non-linearly with respect to matric suction. It is also observed that at the same stress level, the contribution of matric suction towards the strength of the soil is less than the contribution of the net normal stress. These observations are in well agreement with earlier researchers.

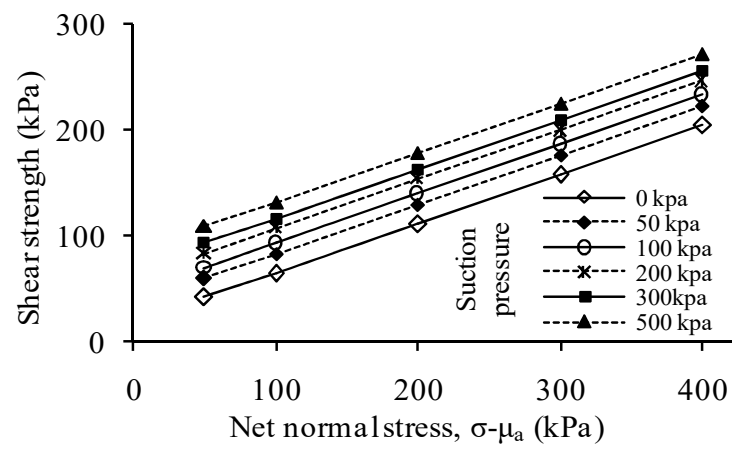

Fig. 5. Shear strength versus net normal stress for different values of matric suction.

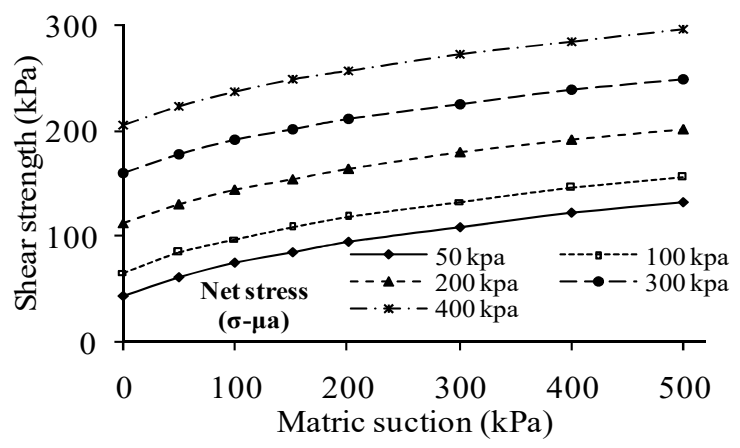

Fig. 6. Variations of shear strength with respect to matric suction for different values of net normal stress.

\subsection{Comparison of the proposed equation with known laboratory test data}

Many researchers mentioned that Vanapalli's model $(1996$ b can be used to describe the suction strength at low suction (e.g., Miao et al. 2002; Kaladelen et al. 2007). Also unsaturated shear strength up to matric suction $500 \mathrm{kPa}$ is the common range of interest in engineering practice. The Vanapalli et al. (1996b) prediction data at low suction range (up to $500 \mathrm{kPa}$ ) are used to examine the validity of the propose equation for this residual soils, which is shown in Fig. 7. Obviously, the proposed and improved equation is fitted very well for this soil.

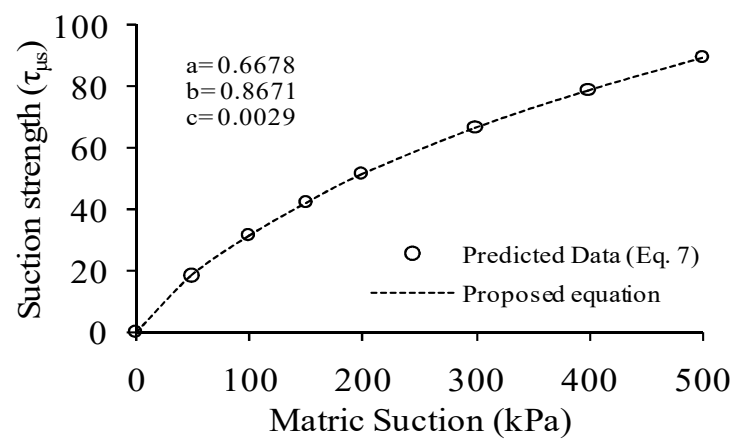

Fig. 7. Suction strength versus matric suction for the studied residual soil. 
Some published unsaturated shear strength data are also used to analyze the validity of the proposed equation. These published laboratory data are extracted from either the graphs or tables of the original publications. A brief summary of these published data is given in Table 3 . The selected soils include undisturbed soil, compacted soil, residual soil and expansive soil with varying plasticity index and grain size distributions. The calculated suction strength using proposed equation is fitted well with the measured suction strength of different types of soils (Fig. 8). Therefore, it can be stated that the proposed improve equation is suitable for different types of soils.

Table 3. Summary of the published data used in this study.

\begin{tabular}{lccc}
\hline \multicolumn{1}{c}{ Authors and Materials } & Soil type & $\mathbf{c}^{\prime}$ & $\boldsymbol{\phi}^{\prime}$ \\
\hline $\begin{array}{l}\text { Vanapalli et al. (1996a) } \\
\text { Compacted Glacial Till }\end{array}$ & $\mathrm{CL}$ & 0 & $23^{\circ}$ \\
\hline $\begin{array}{l}\text { Miao et al. (2002) } \\
\text { Nanyang expansive soil }\end{array}$ & $\mathrm{CH}$ & 32.0 & $21.3^{\circ}$ \\
\hline $\begin{array}{l}\text { Kayadelen et al. (2007) } \\
\text { Diyarbakir residual soil }\end{array}$ & $\mathrm{CH}$ & 14.82 & $21.9^{\circ}$ \\
\hline $\begin{array}{l}\text { Nam et al. (2011) } \\
\text { Roanoke Riverbank silty soil }\end{array}$ & $\mathrm{MH}$ & 15.8 & $32.0^{\circ}$ \\
\hline $\begin{array}{l}\text { Schnellmann et al. (2013) } \\
\text { Molasse basin Silty-sand }\end{array}$ & $\mathrm{SW}-\mathrm{SM}$ & 0 & $33.6^{\circ}$ \\
\hline
\end{tabular}

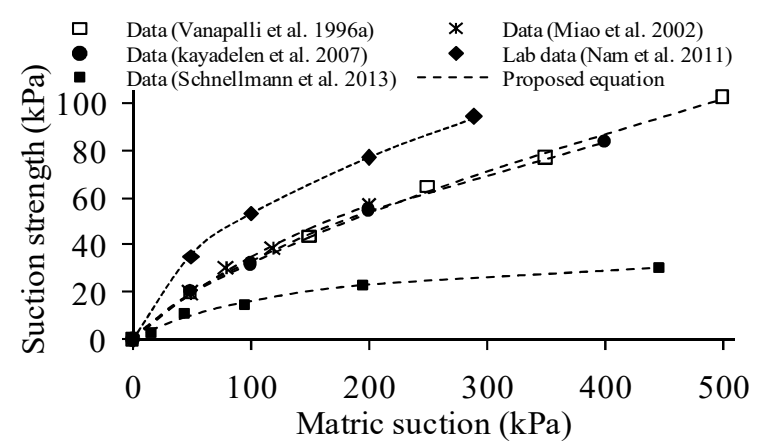

Fig. 8. Fitting curve of proposed equation with published suction strength data of different types of soils.

\subsection{Comparison of several suction strength equations with known laboratory test data}

Guan et al. (2010) mentioned that the fitting type shear strength equations generally provide better estimation than prediction type equations. In this study, Miao et al. (2002) data are used to compare the proposed and some selected published prediction type equations. It can be seen that the proposed equation and Vanapalli et al. (1996 $)$ model provide a better comparison between the predicted and experimental suction strength values whereas Oberg and Sallfors (1997) and Tekinsoy et al. (2004) model provide reasonable comparison and the others published equations provide poor comparison (Fig. 9).
All the selected experimental data are used in the comparison between the proposed and published fitting type equations that are shown in Fig. 10-14. It can be observed that the proposed equation and Jiang et al. (2004) fitting equation provide a better agreement than the other fitting type equations. Shen and Yu (1996) and Miao et al. (2002) fitting equations show better correlation for a particular type of soil but not suitable for all kinds of soils. During the comparison, it is also found that the proposed equation shows the best coefficient of correlation values than the other fitting type suction strength equations.

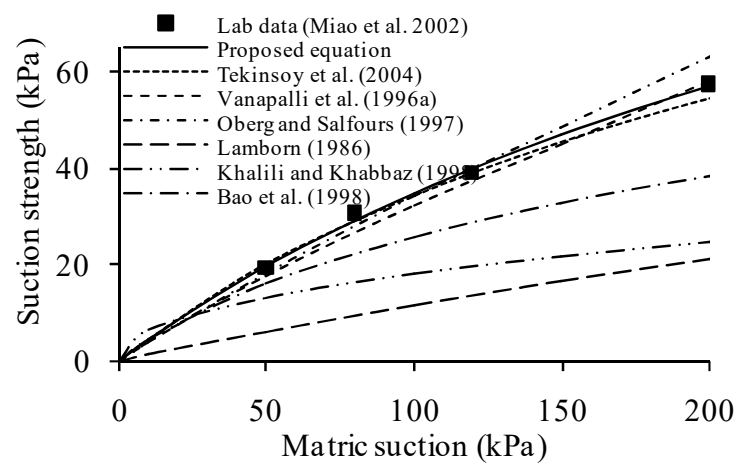

Fig. 9. Comparison of proposed and published predicted type suction strength equations for Nanyang expansive soil.

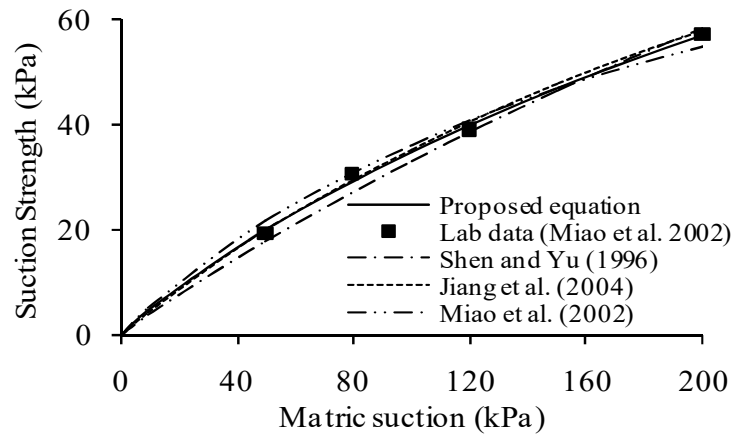

Fig. 10. Comparison of proposed and published fitting type suction strength equations for Nanyang expansive soil.

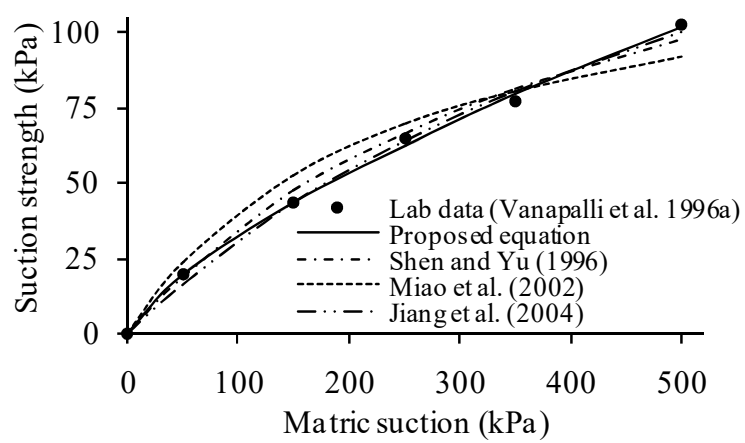

Fig. 11. Suction strength versus matric suction for compacted glacial till. 


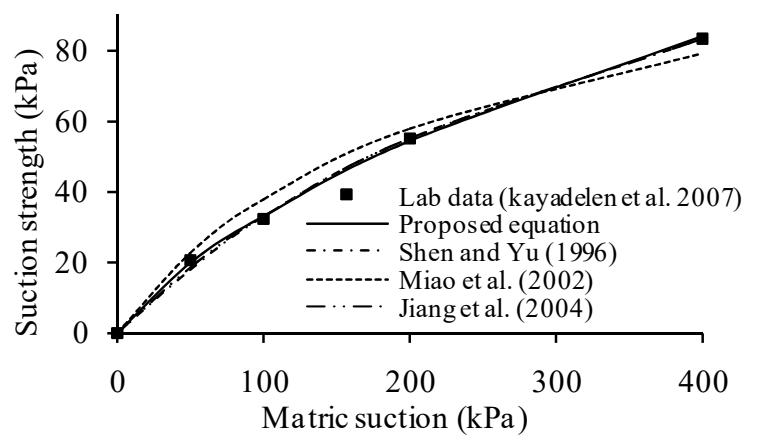

Fig. 12. Suction strength versus matric suction for Diyarbakir residual soil.

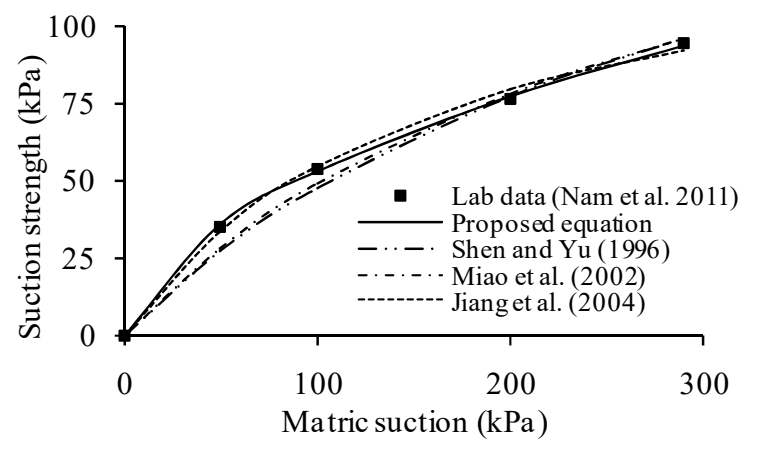

Fig. 13. Suction strength versus matric suction for Riverbank silty soil.

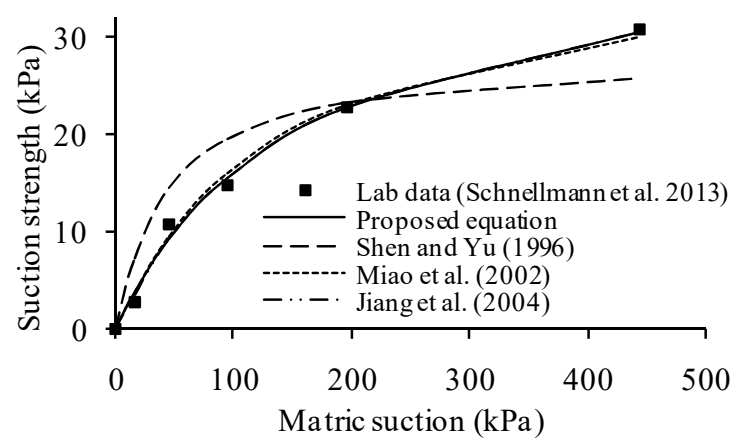

Fig. 14. Suction strength versus matric suction for Molasse basin Silty sand.

From the above analysis, it can be concluded that most of the previously published, predicted and fitting type equations are suitable for particular types of soil. Therefore, the use of the proposed and improved equation is quite adequate for practical engineering purposes and suitable for all kinds of soils.

\section{CONCLUSION}

In this paper, an improved fitting equation is proposed for describing the non-linear behavior of suction strength with respect to matric suction which is the modification of Kong et al. (2005) developed formula for gassy sand. The contribution of matric suction on the shear strength of unsaturated soils is discussed which varies non-linearly with respect to matric suction. The validity of the proposed and improved equation has been tested for experimental results and for a number of unsaturated shear strength data of different types of soils as well as compared with some published suction strength equations. The calculated suction strengths using proposed equation are in well agreement with the experimental data of different types of soils. In addition, the proposed equation provides the best correlation between the calculated and experimental data among all of the fitting type suction strength equations. Therefore, the use of the proposed and improved equation is quite adequate for practical engineering purposes. More tests with high suction need to be carried out to further testify the new model in the future.

\section{ACKNOWLEDGEMENTS}

The authors would like to acknowledge financial support from the National Natural Science Foundation of China (Grant No. 11672320 and 51579237). The first author gratefully acknowledged the $\mathrm{PhD}$ scholarship from CAS-TWAS President's Fellowship Programme.

\section{REFERENCES}

1) Aitchison, G.D. (1961): Relationship of moisture and effective stress function in unsaturated soils, In: Proceedings of the Conference on Pore Pressure and Suction in Soils, Butterworths, London, UK, 47-52.

2) ASTM D7181-11 (2011): Method for Consolidated Drained Triaxial Compression Test for Soils, ASTM International, West Conshohocken, PA.

3) Bao, C.G., Gong, B. and Zhan, L. (1998): Properties of unsaturated soils and slope stability of expansive soil, Keynote lecture, In: Proceedings of the second international conference on unsaturated soils-UNSAT 98, vol 1, Beijing, 71-98.

4) Bishop A.W. (1959): The principle of effective stress, Teknisk Ukeblad 106 (39), 859-863.

5) Bishop A.W. and Blight G.E. (1963): Some aspects of effective stress in saturated and unsaturated soils, Géotechnique, 13 (3), 177-197.

6) Escario, V and Saez, J. (1986): The strength of partly saturated soils, Géotechnique, 36 (3), 453-456.

7) Fredlund, D.G. and Morgenstern, N.R. (1977): Stress state variables for unsaturated soils, ASCE Journal, Geotechnical Engineering Division, 103 (5), 447-466.

8) Fredlund, D.G. and Rahardjo, H. (1993): Soil mechanics for unsaturated soils, John Wiley, New York.

9) Fredlund, D.G., Morgenstern, N.R. and Widger, R.A. (1978): The shear strength of unsaturated soils, Canadian Geotechnical Journal, 15, 313-321.

10) Fredlund, D.G., Xing, A., Fredlund, M.D. and Barbour, S.L. (1996): The relationship of the unsaturated soil shear strength to the soil-water characteristic curve, Canadian Geotechnical Journal, 32, 440-448.

11) Gan, J.K.M., Fredlund, D.G. and Rahardjo, H. (1988): Determination of the shear strength parameters of an unsaturated soil using the direct shear test, Canadian Geotechnical Journal, 25 (3), 500-510.

12) Guan, G., Rahardjo, H. and Choon, L. (2010): Shear strength 
equations for unsaturated soil under drying and wetting, Journal of Geotechnical and Geoenvironmental Engineering, $136(4), 594-606$.

13) Jennings, J.E. (1961): A revised effective stress law for use in the prediction of the behavior of unsaturated soils, In: Proceedings of the Conference on Pore Pressure and Suction in Soils, Butterworths, London, UK, 26-30.

14) Jiang, M.J., Leroueil, S. and Konrad, J.M. (2004): Insight into shear strength functions of unsaturated granulates by DEM analyses, Computers and Geotechnics, 31, 473-489.

15) Kayadelen, C., Tekinsoy, M.A. and Taşkıran, T. (2007): Influence of matric suction on shear strength behaviour of a residual clayey soil, Environmental Geology, 53 (4), 891-901.

16) Khalili, N. and Khabbaz, M.H. (1998): A unique relationship for $\chi$ for the determination of the shear strength of unsaturated soils, Géotechnique, 48 (5), 681-687.

17) Kong, L.W., Guo, A.G., Chen, J.B. and Liu, G.S. (2005): On strength property of gassy fine sand and model tests of pile foundation, Proceedings of the 16th International Conference on Soil Mechanics and Geotechnical Engineering, Osaka, Japan, Millpress Rotterdam Netherlands, 2009-2012.

18) Lambe, T.W., and Whitman, R.V. (1969): Soil Mechanics, John Wiley \& Sons, New York, USA.

19) Lamborn, M.J. (1986): A micromechanical approach to modelling partly saturated soils, M.Sc. Thesis, Texas A \& M University, Texas.

20) Lee, I.M., Sung, S.G. and Cho, G.C. (2005): Effect of stress state on the unsaturated shear strength of a weathered granite, Canadian Geotechnical Journal, 42, 624-631.

21) Miao, L., Liu, S. and Lai, Y. (2002): Research of soil-water characteristics and shear strength features of Nanyang expansive soil, Engineering Geology, Elsevier Science, 65, 261-267.

22) Nam, S., Gutierrez, M., Diplas, P. and Petrie, J. (2011): Determination of the shear strength of unsaturated soils using the multistage direct shear test, Engineering Geology, Elsevier Science, 122, 272-280.

23) Oberg, A.L. and Sallfors, G. (1997): Determination of shear strength parameters of unsaturated silts and sands based on the water retention curve, Geotechnical Testing Journal, 20 (1), 40-48.

24) Rassam, D.W. and Williams, D.J. (1997): Shear strength of unsaturated gold tailings, In: Proceedings of the 1st Australia New Zealand conference on environmental geotechnics, Rotterman: Balkema, 469-74.

25) Sayem, H.M. and Kong, L.W. (2016): Effects of drying-wetting cycles on soil-water characteristic curve, In Proceedings of the 2016 International Conference on Power Engineering \& Energy, Environment (PEEE 2016), Shanghai, China, DEStech publications, Inc, 607-614.

26) Sayem, H.M., Kong, L.W. and Yin, S. (2016): Effect of Drying-Wetting Cycles on Saturated Shear Strength of Undisturbed Residual Soils, American Journal of Civil Engineering, 4(4), 143-150.

27) Schnellmann, R., Rahardjo, H. and Schneider, H.R. (2013): Unsaturated shear strength of a silty sand, Engineering Geology, 162, 88-96.

28) Shen, Z. and Yu, S. (1996): The problems in the present studies on mechanics for unsaturated soils, Proceedings of the symposium on geotechnical aspects of regional soils, Atomic Energy, Nanjing, China, 1-9 (in Chinese).

29) Tekinsoy, M.A., Kayadelen, C., Keskin, M.S. and Söylemez, M. (2004): An equation for predicting shear strength envelope with respect to matric suction, Computers and Geotechnics, 31 (7), 589-593

30) Toll, D.G. and Ong, B.H. (2003): Critical state parameters for an unsaturated residual sandy clay, Géotechnique, 53 (1), 93-103.

31) Van Genuchten, M.T. (1980): A Closed Form Equation for Prediction of the Hydraulic Conductivity of Unsaturated Soils, Soil Science Society America Journal, 44, 892-898.

32) Vanapalli, S.K., Fredlund, D.G. \& Pufahl, D.E. (1996a): The relationship between the soil-water characteristic curve and the shear strength of a Compacted Glacial Till, Geotechnical Testing Journal, GTJODJ, 19, 259-268.

33) Vanapalli, S.K., Fredlund D.G., Pufahl, D.E. \& Clifton, A.W., 1996b, Model for the prediction of shear strength with respect to soil suction, Can Geotech J, 33: 379-392.

34) $\mathrm{Xu}$, Y.F. (1997): Mechanical properties of unsaturated expansive soils and its application in engineering, Ph.D. Thesis, HoHai University, Nanjing, China (In Chinese).

35) $\mathrm{Xu}$, Y.F. (2004): Fractal approach to unsaturated shear strength, Journal of Geotechnical and Geoenvironmental Engineering, 130 (3), 264-273. 